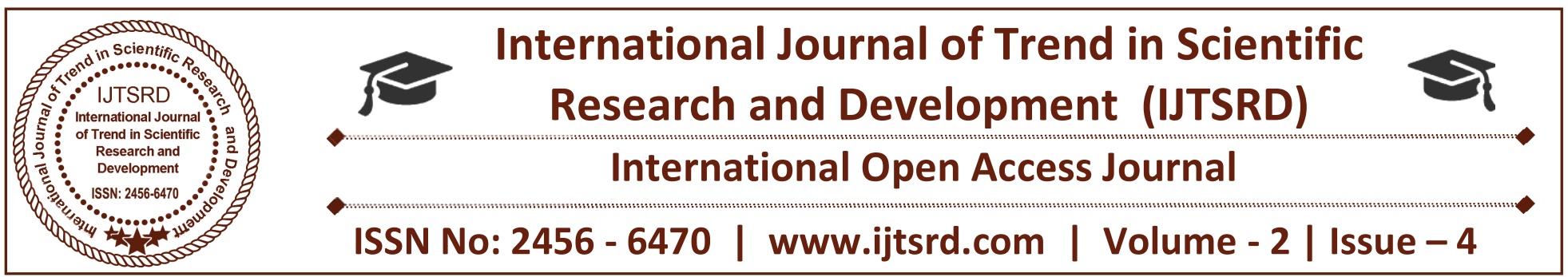

\title{
Hostel Management System
}

\author{
Ritesh Kumar Bista, Aman Jung Karki, Beesu Venkat Mouneesh Reddy, \\ Utkarsh Aakash, Dr. Rajasimha A Makaram, Shilpa Das
}

Department of Computer Science and Engineering, School of Engineering and Technology, JAIN University, Bengaluru, Karnataka, India

\section{ABSTRACT}

The Hostel Management framework is a web application which is created for managing different activities in the hostel. This project is expected to limit human works and make hostel allocation much easier for student and hostel administrators with the help of the web application to hostel, naturally select the student from the waiting list and mess billing, outpass generation, complaint registration, and so forth. Student will get endorsement notice in their mails. It advises guardians with respect to their wards and their presence in hostel and their curricular will be informed to their parents using this model just in one touch. In last, few years the number of educational establishments is expanding quickly. In this way, the quantity of hostels is additionally expanding for the settlement of the student considering in this college. Also, henceforth there is a considerable measure of strain on the individual who are running the hostel and websites are not generally utilized as a part of this specific circumstance. This specific project manages the issues on dealing with a hostel and helps to deal from the issues which happen when conveyed manually.

Keywords: Hostel, RFID, Outpass, Tracking, Mess

\section{INTRODUCTION}

There has been a cosmic increment in the quantity of educational sector particularly over the most recent four decades everywhere throughout the world. This improvement has brought education to the doorstep of individuals. Therefore, it has expanded information and helped create a population of edified residents who can without much of a stretch comply with the principles of civilized society. A large portion of the recently established educational institutions, are utilizing the old ordinary procedures for dealing with all the record keeping and especially for managing hostel facilities. This old method of managing records hence have an adverse effect on the efficiency of the institution. The proposed framework overcomes the disadvantages of traditional techniques for hostel administration; it is easier to use, graphical-UI oriented.

The Hostel Management System is an online site developed for managing different activities in the hostel. It is very easy to use with a user-friendly GUI to automate, arrange and handle all the procedures of managing hostel offices. This is an online site which is developed using HTML and CSS for front end and PHP \& JavaScript for backend. The site will be a great relief to the workers. It is very helpful especially in large institutional organizations with a huge number of hostels. Using this website takes care of all the procedures carried in managing hostels. Developing this website required 4 languages which are:

HTML: HTML is the abbreviation of Hyper Text Markup Language which is a standard markup language used for creating web pages and other information that can be displayed in a web browser. It also consists various tags used for different purpose.

CSS: CSS is the abbreviation of Cascading Style Sheet which is a simple mechanism for adding styles to the web pages. It is designed basically to 
enable the separation of document content from document presentation, including elements such as layout, colors and fonts.

There are 3 types of css:

\section{$>$ Inline \\ $>$ Internal \\ $>$ External}

JavaScript: It is client side scripting language. It is used for interacting with the user like inputting a value from the user. When we want to run any script on the browser then we use JavaScript as a medium.

$>$ PHP: Hypertext Pre-processor is a server-side scripting language designed for web development but also used as a general-purpose programming language.

\section{PROBLEM STATEMENT}

We have 4 hostels in the college, which comprise of 2 boys hostel, one girls hostel and dormitories. Every one of these hostels are handled through manual operation by the hostel office. The Registration frame confirmation to the various information processing are done physically. In this way, there are a great deal of redundancies which can be effectively avoided. Subsequently there is a lot of strain on the individual who are running the hostel and web applications or software's are not generally utilized as a part of this specific circumstance. This project manages the issues on dealing with a hostel and stays away from the issues which happen when handled physically. Designing a computerized system with the userfriendly GUI, and efficient performance by identifying the drawbacks of the existing system will help to overcome the problems of existing system.

\section{BACKGROUND WORK}

In the paper [1], they have created PHP-MySQL source code which would help in building up the Online Hostel Management System. It diminishes the efforts made by the hostel chief and hostel proprietor while managing the hostel. It removes the pen and paper idea which is being utilized by us from before times. The created framework gives solution for manual hostel administration issues and furthermore gives data, for example, hostel data, hostel room data, and hostel accounts data. It is online programming/site so anybody can get to it from anyplace with no unpredictability with the assistance of a working web association.

The author of paper [2] proposed, E-registrations outlined was anything but difficult to streamline the student' undertakings/doormen's activity. The stages required with the registration procedure must be reduced to closest possible if the system needs to be fast and more efficient and convenient. Paper-based procedures of registration are tedious and costly. Eregistration for hostel facility played a major part in the change and thus helped to achieve the following:

Reduced the paper work and redundancy thereby improving productivity and lowering cost of printing and purchasing registration materials annually.

Aid the hostel in data management and integration of students profiles.

Provided the hostel's statistics on the need of students (e.g. tables, chairs, etc.).

Aid the hostel to give account of student with ease at any time.

In this paper [3], author gives a study on RadioFrequency Identification (RFID) technology. At first RFID labels were created to replace barcode readers in supply chains. RFID tags, or basically "tags", are little transponders that react to inquiries from a reader by remotely transmitting a serial number or similar identifier. RFID have two vital segments for the most part one is tag and other is antenna. Tags have an inserted transmitter and receiver. A RFID tag works as, the receiver of the RFID device generates an electromagnetic radiation which induce current in to the antenna of tag. The paper surveyed on the RFID device. RFID technology has a major potential to wind up universal sooner rather than later. Today it is as of now effectively utilized as a part of inventory network administration to track. It helps us to track any item or thing or a human being by implementing in a correct way and also helps to save time without the involvement of no human work.

In the paper [4], author talks about security in this day is one of the major difficulties that individuals are confronting everywhere throughout the world in each part of their lives. Information to any association is a most valuable property. Security of sensitive information is dependably a major test for an 
association at any level. In the present technological world, database is helpless against hosts of assaults. In this study, significant security issues confronted databases are recognized and some encryption strategies are talked about that can remove the assaults hazards and ensure the delicate information. To wipe out the security dangers each association must define a security approach and that security approach ought to be strictly enforced. A strong security strategy must contain very much characterized security features, access control, Inference Policy, User Identification/Authentication, and Encryption.

\section{SCOPE AND LIMITATIONS:}

$>$ Hostel Managements System is intended for Hostel (like schools, colleges).

$>$ There will be pre-characterized criteria for the Reserve to the hostels.

$>$ He checks the bore witness to application types of the student acquired from the web and confirm it with the student database.

If the students are qualified then they are designated to the hostel Room.

\section{OBJECTIVES}

Major objective of the proposed system is to help automating basic hostel management activities. The basic hostel management activities comprise of activities like:

Admin can send the approval notice to the students through mail system.

$>$ Insert the student details and other records.

Students can enroll their complaints in complaints page.

- Hostel employee can calculate the hostel accounts in an easy manner.

Hostellers can check the status of their hostel fee.

Room Allotment to the hostellers.

Student's movement tracking through RFID

Outpass application for the students.

Providing data integrity of the student using approved login
To display daily mess schedule managed by the admin

Mail notifications to the student, guardians, and other hostel worker.

$>$ Providing simultaneousness access to the site.

\section{EXISTING SYSTEM}

Current situation of hostel administration framework is all the work is done physically. Various information or record copies of the hostel and student data are kept in various divisions. Room is distributed by the room necessities and as per requested by the student. Hostel offices and other data are altogether kept in a booklet or is shown on notice board. Student's data, staff data, student registration, room status, complaints, occasions news, outpass application are kept in registers and requires manual entry.

\subsection{Limitations of Existing system}

The current framework makes the data retrieval very difficult because of huge volume of document.

Data security and Integration are major concern in current system

Current framework is powerless against natural disasters which causes loss of data.

The current framework does not have a PC based database for storing of documents

The entire process is tedious and a waste of human and material assets.

Record management and searching is a very difficult job.

\section{PROPOSED SYSTEM}

To overcome all the limitations of the existing system, a framework called hostel management is proposed which is a web application. This framework automates all the activities occurring in the hostel. The proposed system provides data security and integration which is a major drawback in the current scenario and also provides smooth operation in retrieving data in a more systematic way hence saving a lot of human effort and time.

The proposed system being a website runs on a server with robust database with eliminates the problem of 
data redundancy and helps to store information of students and other hence ensures data integrity and interconnects all those students and management process involved. This framework allows students and employee to manage various activities in a computerized manner. This system also incorporates the use of RFID device which keeps the track of student's movement in the hostel using the tag and receiver.

\subsection{Working of RFID:}

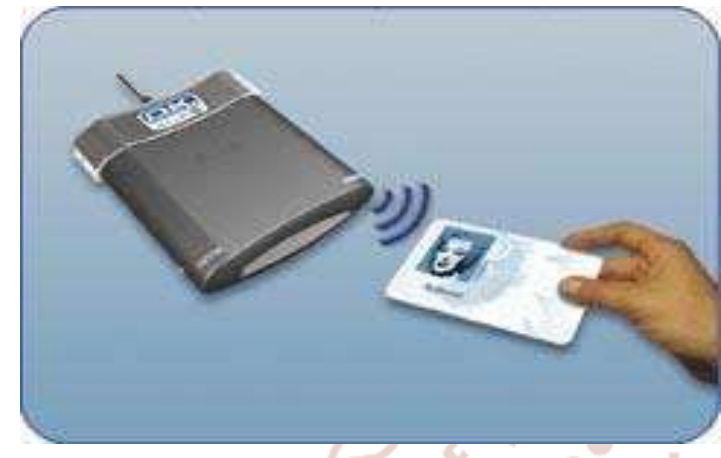

Fig 7.1 (a): RFID Tag and Receiver

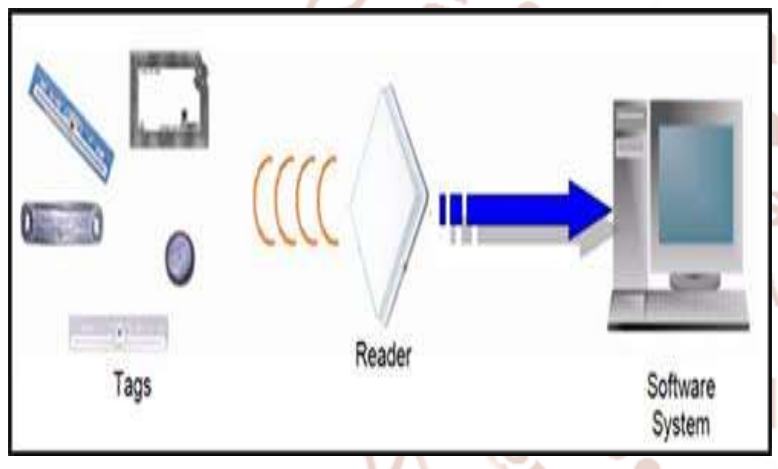

Fig 7.1 (b): RFID Working Process

\subsection{DFD of Hostel Management System:}

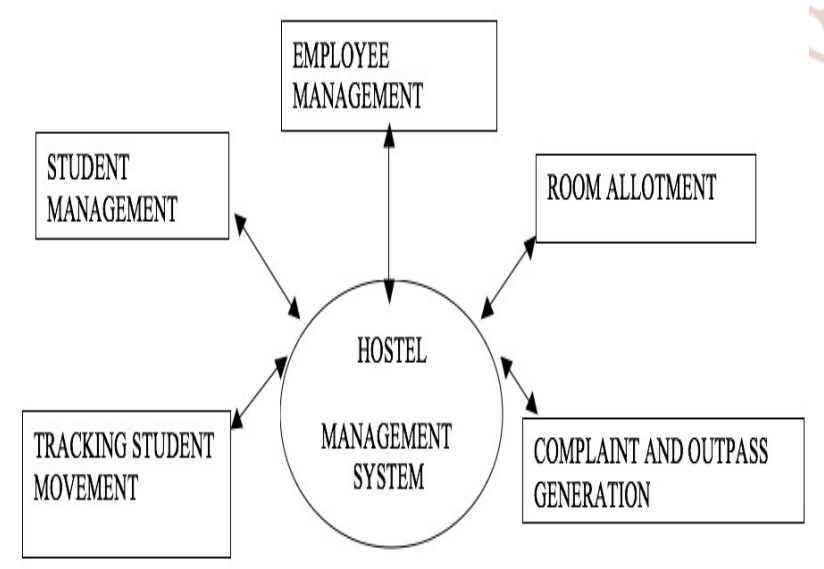

Fig 7.2: DFD
7.3 System Modules:

The proposed framework consists of three different modules:

\section{Administrator}

Employee/Warden

Student

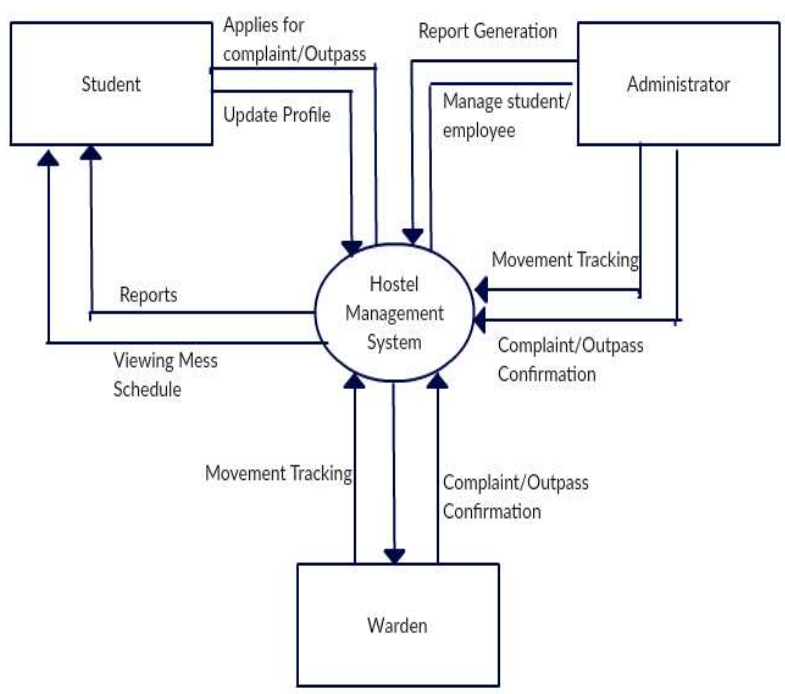

Fig 7.3: System Architecture

\subsubsection{Administrator Module:}

This module consists of following functionalities:

Login to administrator module: Only authorized user is allowed to access the information to the website once he/she verifies themselves by providing user account and password.

Profile: User can view and update their profile to make any changes. They can also change their password which requires old password.

Rooms: This page has many functionalities. Here user can add rooms, allot rooms to the students, view room allotment and change or remove the rooms.

Students: This page allows user to manage students. User can add students, update their details, add mess card for the students. Also, they can track movement of the student using RFID device. 
Employee: Only administrator has the authority to add and manage employee.

Reports: In reports user can approve or reject the applications of the students regarding the complaints, outpass. Also, they can generate reports on mess bill, mess cards, hostel bills.

Mess Schedule: In this page user can update daily mess routine which will be updated in the student profile.

\subsubsection{Warden Module}

This module will contain the following functionalities:

Login to Warden module: Only authorized user is allowed to access the information to the website once he/she verifies themselves by providing user account and password.

$>$ Profile: User can view and update their profile to make any changes. They can also change their password which requires old password.

> Rooms: This page has many functionalities. Here user can add rooms, allot rooms to the students, view room allotment and change or remove the rooms.

Students: This page allows user to manage students. User can add students, update their details, add mess card for the students. Also, they can track movement of the student using RFID device.

$>$ Reports: In reports user can approve or reject the applications of the students regarding the complaints, outpass. Also, they can generate reports on mess bill, mess cards, hostel bills.

Mess Schedule: In this page user can update daily mess routine which will be updated in the student profile.

\subsubsection{Student Module}

This module will contain the following functionalities:

Login to Student Profile: Only authorized students are allowed to access the information to the website once he/she verifies themselves by providing user account and password.
View Profile: Students can only view their profile and are not allowed to make any changes. If any changes they want to make, they must approach to administrator or warden.

Change Password: Students can change or update their password by entering old and new password.

Complaint Registration: Students can make register complaints regarding various hostel facilities like furniture, electrical, plumbing, others. Once confirmed student will get a mail notification from warden or administrator.

Outpass Application: Students can also apply for outpass required to go for outing from the college. Once confirmed student will get a mail notification from warden or administrator.

Outpass Log: In this function student can view their logs regarding outpass status.

Complaint Log: In this page student can view their logs regarding complaint status.

Movement Log: This page provides student details with number of times they went outside and came inside the hostel with time and date.

View Mess Schedule: Student can view daily mess schedule through this page.

\subsection{Use Case Diagrams:}

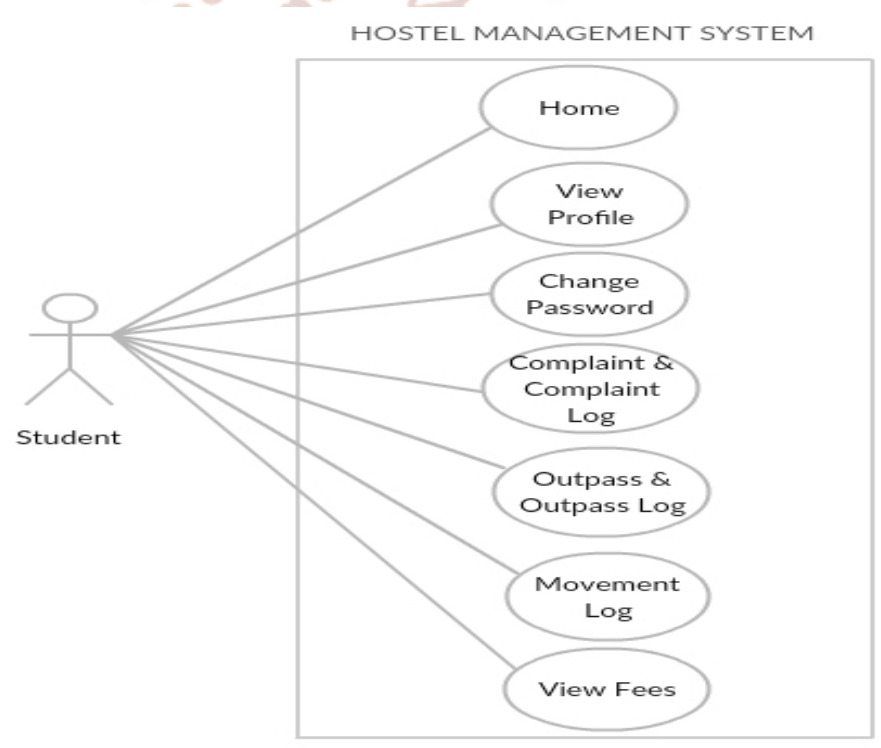

Fig 7.4 (a): Student Use Case Diagram 


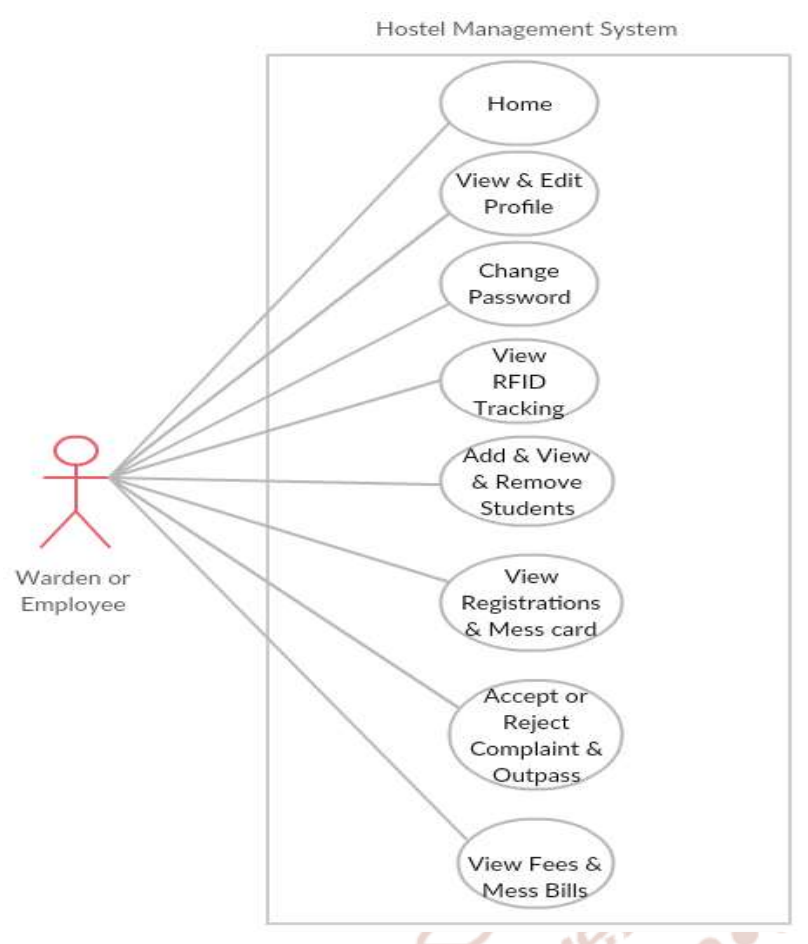

Fig 7.4 (b): Warden Use Case Diagram

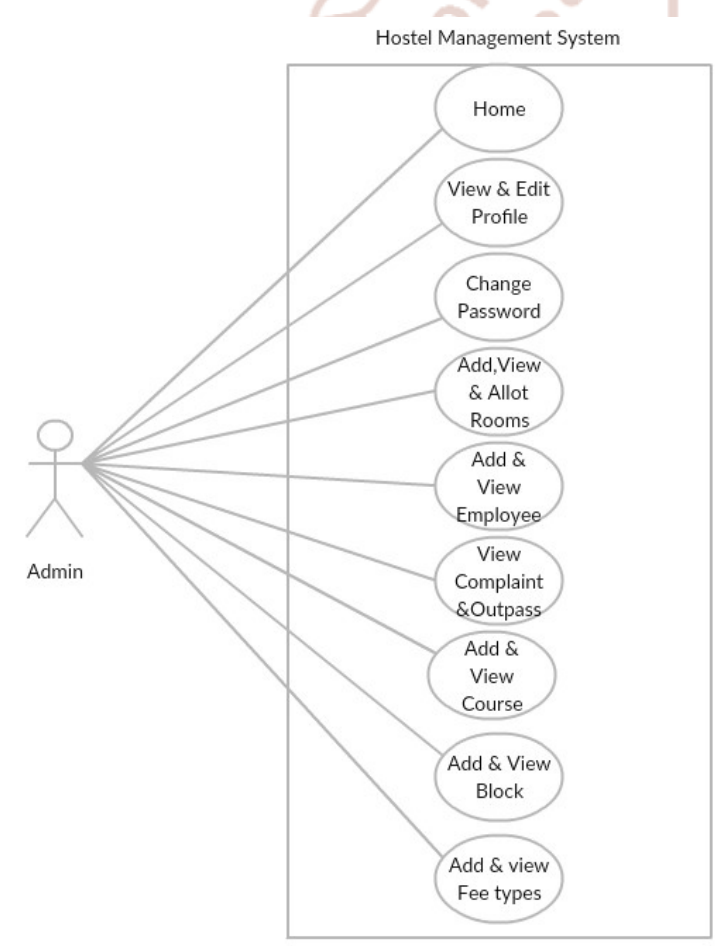

Fig 7.4 (c): Admin Use Case Diagram

\subsection{Benefits of the Proposed System}

Automates all the activities involved in maintaining hostel administrations.

The utilization of database will help in simple retrieval of data and control information concurrency.
Provides data integration and privacy through authentication of each user.

$>$ Student movement on the hostel can be tracked.

$>$ It is cost effective as information's are stored online and can be accessed remotely hence eliminating record keepings.

$>$ Mail notification for every events, notice and approval status of various activities (outpass, complaints, etc).

\subsection{Limitations of Proposed System}

The above proposed system has some of the challenges listed below which can be addressed.

dThe seller might not get best price for the product if there won't be many buyers to bid on because of which the product might go on less price.

Buyers might not be aware of the auction timing. As seller can create auction at any period of time.

Both buyers and sellers should be mobile friendly. If the user don't know how to use mobile it will be difficult to the user to use the application.

As it is online process, the users must be connected to the internet to access the auction and to buy/sell the product.

Required product might not be available on time as it depends upon the seller to which product he/she wants to sell.

Delivering the product might take some time depending upon the address of the buyer and seller.

\subsection{Hardware and Software Tools}

\begin{tabular}{|l|l|}
\hline $\begin{array}{l}\text { Hardware } \\
\text { Requirements }\end{array}$ & $\begin{array}{l}\text { Processor - i3 } \\
\text { Hard Disk - 5 GB } \\
\text { Memory - 1GB RAM }\end{array}$ \\
\hline $\begin{array}{l}\text { Software } \\
\text { Requirements }\end{array}$ & $\begin{array}{l}\text { LAMP, MAMP, } \\
\text { WAMP, XAMP }\end{array}$ \\
\hline Platform & $\begin{array}{l}\text { Windows XP, Windows } \\
\text { 7, Other Latest Platform }\end{array}$ \\
\hline $\begin{array}{l}\text { Programming } \\
\text { Language/Tools }\end{array}$ & $\begin{array}{l}\text { HTML, JavaScript, } \\
\text { PHP, } \underline{\underline{\text { MYSQL,CSS }}}\end{array}$ \\
\hline
\end{tabular}

Table 7.7: Hardware \& Software tools 


\section{CONCLUSION}

In short about the proposed framework, the project created utilizing HTML, PHP, JavaScript and MySQL is in light of the prerequisite detail of the user and the research of the current framework, with adaptability for future improvement. The functionality of the present programming requires a proper approach towards programming advancement. This Hostel administration website is intended for individuals who need to handle different activities in the hostel. As from last few years numbers of colleges/universities are increasing and so is students number which require an automated system which can reduce human effort and make administration easy and in more technological way.

\section{REFERENCES}

1. Bikash Choudhary, Deepak Kumar, Deepika Priyadarshini Khatua, Ajit Kumar Patro, "Online Hostel Management System"

2. O. Shoewu; S.A. Braimah; and O. Duduyemi, "Design and Implementation of Hostel Management System (HOMASY): LASU as Case Study"

3. Christoph Jechlitschek, "A Survey Paper on Radio Frequency Identification (RFID)" Iqra Basharat, Farooque Azam, "Database Security and Encryption: A Survey Study", International
Journal of Computer Applications (0975 - 888) Volume 47- No.12, June 2012.

4. Felke-Morris. Basics of Web Design: HTML5 \& CSS3, 2nd Edition, Addison-Wesley, 2013.

5. Jatinder Manhas," A Study of factors Effecting websites page loading speed for efficient web performance", IJCSE ,Vol 1 ,Issue 3,Nov 2013.

6. Chandra M, Ramani A.V,"A Study on website quality evaluation based on sitemap", IJCSE, Vol 2,Issue 2,Feb 2014.

7. Roy Want, "An Introduction to RFID Technology”, 1536-1268/06, 2006 IEEE.

8. Ayanlowo, K., Shoewu, O., Olatinwo, S. O., Omitola, O. O., \& Babalola, D. D. (2014). Development of an Automated Hostel Facility Management System. Journal of Science and Engineering, 5(1), 01-10.

9. Radhakrishnan, R. (2014). Online hostel management system (doctoral dissertation, cochin university of science and technology)

10. Wan Jr Jaafar, W.N.H.(2012). HOSTEL MANAGEMENT SYSTEM (HMS), report for bachelor of computer science degree, Universitiy Malaysia Pahang, online, accessed on 9-11-2016

11. Segun O. Olatinwo and et al. 2014. "Development of an Automated Hostel Facility Management System". Journal of Science and Engineering. 5 (1): $1-10$. 